\title{
NUMERICALANALYSIS OF BOND BEHAVIOR BETWEEN MASONRY BRICKS AND COMPOSITE MATERIALS
}

\author{
BahmanGhiassi, ${ }^{1}$ GiancarloMarcari, ${ }^{2}$ Daniel V. Oliveira, ${ }^{3}$ Paulo B. Lourenço ${ }^{4}$ \\ ISISE, University of Minho, Department of Civil Engineering, Guimarães, Portugal
}

\begin{abstract}
Fiber Reinforced Polymers have become a popular material for external strengthening of masonry structures. The performance of this strengthening technique is strongly dependent on the bond between FRP and substrate. This paper presents numerical modeling of the bond behavior in FRP-strengthened masonry components using interface elements, based on a recent testing program at the University of Minho. A trilinear bond-slip model is proposed for the interface elements based on observed experimental behavior of strengthened components. The comparison between numerical and experimental results shows that the proposed model is suitable for numerical simulation of the bond behavior and allows a better understanding of the mechanisms involved in the failure process.
\end{abstract}

Keywords: Masonry; composite materials; bond; interface elements; FE analysis;

${ }^{1} \mathrm{PhD}$ Student, ISISE, University of Minho, Department of Civil Engineering, Azurém, 4800-058 Guimarães, Portugal. Phone: +351 253517 215, fax: +351 253510 217, Email: bahmanghiassi@ civil.uminho.pt ${ }^{2}$ Assistant Researcher, ISISE, University of Minho, Department of Civil Engineering, Azurém, 4800-058 Guimarães, Portugal. Phone: +351 253510 498, fax: +351 253510 217, E-mail: marcarigia@ civil.uminho.pt ${ }^{3}$ Associate Professor, ISISE, University of Minho, Department of Civil Engineering, Azurém, 4800-058 Guimarães, Portugal. Phone: +351 253510 247, fax: +351 253510 217, E-mail: danvco@ civil.uminho.pt

${ }^{4}$ Professor, ISISE, University of Minho, Department of Civil Engineering, Azurém, 4800-058 Guimarães, Portugal. Phone: +351 253510 209, fax: +351 253510 217, Email: pbl@ civil.uminho.pt 


\section{INTRODUCTION}

Composite materials, such as Fiber Reinforced Polymers (FRP) and Fiber Reinforced Grouts (e.g. SRG), have been used extensively for external strengthening of masonry structures in recent years. The effectiveness of this strengthening technique is intrinsically dependent on the bond performance between the composite material and the masonry substrate. As the bond is a key mechanism in transferring the stresses from structural elements to the composite material, its failure results in deterioration of the strengthening system or premature debonding. Although the bond behavior in FRPstrengthened concrete has been extensively studied experimentally and analytically [111], a detailed understanding of aspects such as failure initiation, nonlinear bond mechanisms, and constituent property effects on local phenomena is still under development in the case of masonry substrates [12-21].

Significant progress has been achieved in the last years in the development of refined computational approaches to investigate the debonding mechanism and damage in FRP-strengthened concrete [5-11] and masonry [18-21] elements or analysis of fullscale strengthened structures [22-25]. Numerical models usually follow two main approaches. In the first approach, the bond behavior is modeled using a zero thickness interface element between FRP and substrate [6-9, 18, 19]. Within this approach the nonlinearities are usually concentrated at the FRP-substrate interface, while FRP and substrate are characterized by an elastic behavior. This approach is attractive, in principle, since it can potentially capture the critical aspects related to interfacial mechanics and bond failure initiation and propagation by using suitable interface (bondslip) laws. Bond-slip laws are generally provided by relevant standards (e.g. [26]) or can be obtained experimentally on the basis of simple shear bond tests. However, this 
approach is unable to provide information on $3 \mathrm{D}$ effects of the debonding mechanism. The critical aspects that still need to be elucidated include the accurate prediction of strain distribution (local level) and force-slip evolution (global level), especially when the structural response becomes nonlinear. The second approach consists of the cracking and failure of all constituents according to a meso-scale model $[10,11,20,21]$. An advantage of this approach is that the complex stress conditions and interaction of cracks observed in real structural systems can be simulated. But as a disadvantage, this approach requires many parameters related to the constituent properties (pertaining to substrate, adhesive, and FRP), which affects its application in engineering usage and poses questions about the availability and selection of relevant data.

This paper deals with the numerical analysis of experimental single-lap shear tests of composite materials glued on brick samples carried out at the University of Minho [27]. The main object is to simulate the nonlinear bond behavior of brick specimens strengthened with Carbon (CFRP), Glass (GFRP), and Basalt Fiber Reinforced Polymer (BFRP) as well as Steel Reinforced Polymer (SRP) composites with respect to local strain distribution and global force-slip curves. BFRP and SRP are presented as innovative materials for strengthening masonry structures.

A 2D plain stress finite element model is used for studying the delamination problem in this study. The bond behavior has been modeled using interface elements with a trilinear interfacial constitutive model which is proposed based on the presented experimental tests. The obtained numerical results are then presented and discussed critically. The validity of the approach is assessed through a comparison with experimental data. It is shown that the FE simulations are in satisfactory agreement with the experimental results, in terms of force-displacement curves, strain distribution along the bonded length, and failure mode. The proposed bond-slip model is also compared 
with the bond-slip model proposed by the Italian design code CNR DT200 [26] as an example of available relevant standards.

\section{BRIEF DISCUSSION OF EXPERIMENTAL PROGRAM}

\subsection{Tests description}

Single-lap shear bond tests have been performed at the University of Minho on masonry bricks strengthened with different epoxy based composite materials, namely carbon, glass, basalt, and steel [27]. The FRP/SRP strips of $50 \mathrm{~mm}$ width were applied on masonry bricks following the wet layup procedure. The bonded length of the strips was equal to $160 \mathrm{~mm}$ with a $40 \mathrm{~mm}$ unbounded part at the loaded end, as illustrated in Fig. 1. Six specimens were tested for each type of composite material.

The tests were performed using a closed-loop servo-controlled testing machine under displacement controlled conditions. The displacements were imposed following a constant speed of $5 \mu \mathrm{m} / \mathrm{min}$ at the end of the FRP strip. The resulting load was measured by means of a load cell, while the strain distribution was obtained from four strain gauges attached to the composite material surface, see Fig. 1. In particular, three strain gauges were glued on the bonded area and one was glued on the unbounded area.

The masonry units used as the substrate were clay bricks with dimensions of 250 $\times 120 \times 55 \mathrm{~mm}^{3}$, a mean compressive strength of $19.75 \mathrm{MPa}(\mathrm{CoV}=2.5 \%)$, a tensile strength of $2 \mathrm{MPa}(\mathrm{CoV}=4 \%)$, and modulus of elasticity of $5579 \mathrm{MPa}(\mathrm{CoV}=5.2 \%)$. The compressive strength values of the bricks were kindly provided by the University of Padova in the framework of RILEM TC 223-MSC [27]. The experimentally obtained mechanical characteristics of the composite materials are shown in Table 1 in terms of modulus of elasticity, $E_{f}$, tensile strength, $f_{t}$, ultimate deformation, $\varepsilon_{\max }$, and composite thickness, $t_{f}$.

\subsection{Experimental results}


The local bond stress-slip ( $\tau-s)$ curves have been obtained from the experimental strain profiles measured along the FRP reinforcement at different load levels based on the approach given in [15], see Fig. 2. In fact the bond stress distribution within the bonded length can be evaluated by imposing the equilibrium condition of an FRP strip with a length $d \mathrm{x}$ bonded to masonry, assuming an elastic behavior of the reinforcement, as:

$$
\tau(x)=t_{f} E_{f} \frac{d \varepsilon_{f}}{d x}
$$

where $d \varepsilon_{f} / d x$ is the gradient of FRP strain along the sheet length captured by the strain gauges, $E_{f}$ is the FRP elastic modulus, and $t_{f}$ is the FRP thickness. Moreover, the slip at distance $x$ from the free end of the specimen can be calculated assuming a zero slip in the free end as:

$$
s(x)=\int \varepsilon_{f} d x
$$

As the strain values along the element are captured in a discrete form, the bond stress and slip values can be approximated numerically as:

$$
\begin{aligned}
& \tau\left(x_{i}\right)=\frac{1}{2} E_{f} t_{f}\left[\frac{\varepsilon_{f}\left(x_{i}\right)-\varepsilon_{f}\left(x_{i-1}\right)}{x_{i}-x_{i-1}}+\frac{\varepsilon_{f}\left(x_{i+1}\right)-\varepsilon_{f}\left(x_{i}\right)}{x_{i+1}-x_{i}}\right] \\
& s\left(x_{i}\right)=\frac{1}{2} \sum_{k=1}^{i}\left[\varepsilon_{f}\left(x_{k}\right)+\varepsilon_{f}\left(x_{k-1}\right)\right]\left(x_{k}-x_{k-1}\right)
\end{aligned}
$$

The local bond-slip behavior ( $\tau-s$ curve) along the bonded length in the tested specimens, which is used in this study as the basis for the adopted bond-slip model, can be obtained analytically using Eqs. (3) and (4). Furthermore, the total relative displacement of the composite strip can be obtained using Eq. (4) and assuming that the strain at the loaded end is given by strain gauge 4 placed in the unbounded zone. This evaluation is based on the assumption that strain is constant along the unbounded zone. 
The analytical $\tau-s$ curves may show some irregularity as they are obtained based on discrete and limited strain readings. While numerical integration has a smoothing effect, numerical differentiation tends to magnify these irregularities [15].

The strain profiles shown in Fig. 2 are for different load levels of 20\%, 40\%, $60 \%, 80 \%$, and $100 \%$ of the ultimate load. As can be seen, for low load levels the strain profiles follow an exponential curve, indicating that the load transfer occurs along a short length close to the loaded end. With an increase in the load level, longer load transfer lengths are mobilized, which is in agreement with the behavior observed by other authors [12-17].

The local bond-slip curves of the specimens have been obtained by means of Eqs. (3) and (4) using the strain distributions obtained from the experimental tests (Fig. 2). As an example the envelope of the local bond-slip behavior near the loaded end (strain gauge 3 in Fig. 1) is shown in Fig. 3 for each composite material. From visual observation it can be noted that a similar overall behavior is found for different composite materials with small differences in bond strength and slip. The bond-slip curves in all the specimens follow a trilinear trend with a plastic branch in the middle. Based on this observation, a trilinear bond-slip law has been adopted for numerical analyses, which is described in the next sections.

The global force-relative displacement behavior of the specimens has been obtained using the force-slip values at the loaded end of the specimens in each step. The resulting curves are shown in Fig. 4 for all the specimens. A relatively ductile behavior is observed in the force-relative displacement curves for all FRP types.

In order to obtain better insight into the experimental results, a comparison is made between different FRP composites by illustrating the envelopes of force-relative displacement curves in Fig. 5. It can be seen that the specimens strengthened with CFRP 
and SRP have similar global behavior, while some similarity also exists between BFRP and GFRP strengthened specimens. In general, BFRP and GFRP specimens have lower strength and higher ductility than CFRP and SRP. This result seems to be a direct consequence of the mechanical and geometrical properties of the composite materials, see Table 1, and will be further discussed with the assistance of numerical modeling.

In all specimens, delamination of the FRP strip with a thin and uniform layer of brick (approximately $1 \mathrm{~mm}$ ) was observed.

\section{NUMERICAL MODELING OF SHEAR BOND TESTS}

Since the tensile strength of brick is lower than that of the epoxy resin, debonding in FRP-masonry elements under pull-out or peeling stresses must occur in the brick or FRP-brick interface. The thickness of the debonded material in the tests was very small in comparison to the unit thickness. Therefore, it seems reasonable to assume that the damage can be modelled as interfacial debonding by using interface elements between FRP and masonry. This approach allows a significant reduction of the analysis time and use of a simpler mesh, while producing suitable results in the presence of an appropriate bond-slip law.

It is assumed that the FRP sheet and masonry unit are linear elastic materials and the nonlinearity of the strengthened component is concentrated in the interface region. The accuracy of the results in this modeling approach depends on the adopted bond-slip law for the interface elements, which should be a function of the adhesive type, bonded area, and FRP and substrate mechanical properties. However, it can also be obtained directly from the results of shear bond tests as described in Section 2.2. 


\subsection{Finite element model}

The numerical analysis has been performed with a plane stress finite element model in the FE code DIANA [28], see Fig. 6. The adopted mesh includes eight-node plane stress elements (labelled as CQ16M in DIANA) for representing the masonry unit, two-node truss elements (labelled as L2TRU in DIANA) for the FRP strip, and six-node zerothickness interface elements (labelled as CL12I in DIANA) for the FRP-brick interface. The constraints and loading conditions are applied to the model as shown in Fig. 6. An incremental monotonic displacement load is applied to the free end of the FRP strip for simulating the test conditions. A modified Newton-Raphson iterative scheme together with the line search method is used for solving the nonlinear equations.

\subsection{Material models}

\subsubsection{Brick and FRP constitutive model}

Isotropic elastic material models are used for brick and FRP sheets. The validity of this assumption is discussed comprehensively in Section 3.4. The mechanical properties selected for brick and FRP sheets are those obtained from the tests, see Section 2.1.

\subsubsection{Interface constitutive model}

Although the interfacial behavior has been the subject of many studies and different bond-slip laws have been proposed for FRP-concrete elements [4-7], this information for FRP-masonry received far less attention. Bond-slip models used for FRP-concrete components can be categorized as linear [4], bilinear [5], and nonlinear types [6, 7], as shown in Fig. 7. As the available results on FRP-masonry bonds are scarce, bond-slip models similar to the ones proposed for FRP-strengthened concrete elements have been used $[18,19]$.

In this study, a bond-slip model has been proposed based on the observed local bond response of specimens, see Fig. 8. The adopted bond-slip model is defined by four 
parameters being bond strength, $\tau_{\max }$, the slip value corresponding to the elastic limit, $s_{\circ}$, the slip at the end of the plastic branch, $s_{1}$, and the ultimate slip, $s_{u}$. These parameters have been obtained for each composite material by performing a parametric study to obtain the best global (force-relative displacement behavior) and local (strain distribution along the bonded length) responses in comparison to the experimental results. The values adopted for these parameters are shown in Table 2.

\subsection{Analysis results}

The numerical results are compared with the experimental ones in Fig. 9 to Fig. 11 in order to assess the reliability of the proposed model.

Figure 9 shows the comparison between the global force-relative displacement curves obtained from numerical analysis and the envelope of the experimental results. The numerical results fit the experimental results with reasonable accuracy. It can be seen that the bond strength, bond stiffness, and ductility have been simulated reasonably.

Accurate prediction of strain distribution along the bonded length is crucial in predicting the evolution of debonding and computing the effective transfer length, which are key issues in design procedures. It was observed in this study that the adopted bond-slip model plays an important role in predicting the strain distribution along the bonded length of the FRP sheets and its proper selection is crucial in delamination problems. Figures10 and 11 show that the numerical strain distribution along the bonded length is in good agreement with the corresponding experimental values captured by the strain gauges. The comparison is made for the load levels of $40 \%$ and $80 \%$ of the maximum load, corresponding to moderate and high levels of nonlinear behavior, respectively. To the knowledge of the authors, in the previous studies this 
comparison was usually made at low load levels such as $20 \%$ of the ultimate load in [19].

A comparison of the experimental local bond-slip behavior with the adopted bond-slip model is shown in Fig. 12. It can be observed that the proposed bond-slip model fits the experimental bond behavior quite well.

The results show that the BFRP- and GFRP-strengthened specimens have shear fracture energies comparable to CFRP-strengthened specimens, which can be attributed to the same failure mechanism, see Table 2. BFRP- and GFRP-strengthened specimens exhibit high ductility, while SRP- and CFRP-strengthened specimens show lower ductility, see Fig. 9.This similarity also exists in the case of effective transfer length. The effective transfer length in BFRP- and GFRP- strengthened specimens is around 80 $\mathrm{mm}$ and it is $120 \mathrm{~mm}$ in SRP- and CFRP-strengthened specimens, see Figs 10, and 11.

\subsection{Verification of the model assumptions}

As described before, the main assumption made in this modeling approach is that the brick and FRP composite materials are elastic and all the nonlinearities are concentrated in the interface region. This assumption is verified in this section by investigating the stress fields in the FRP and masonry brick.

The normal stresses along the FRP composites are captured in the ultimate stage of the nonlinear analysis and their variation along the FRP strip is shown in Fig. 13. The maximum stress values are considerably lower than the tensile strength of FRP composites given in Table 1, which confirms the elastic behavior of FRP strips in the analysis. This figure also shows that the maximum stress developed in the FRP sheets is almost the same for all FRP types, which can be attributed to the same failure mode observed in all specimens. 
The maximum principal stress distributions in the bricks are also controlled in the ultimate stage of the nonlinear analysis, see Fig. 14. As expected, with the exception of very localized peak values, the tensile stresses in the bricks are lower than their corresponding strengths.

The analysis of the obtained results seems to confirm that FRP composites and bricks are in their elastic regime.

\section{DISCUSSION ON GUIDELINES PROVISIONS}

The proposed trilinear bond-slip model is compared with the bond-slip model proposed in the Italian CNRDT200 provisions [26] in this section. CNR DT200 proposes a bilinear bond-slip model as illustrated in Fig. 15. This model is provided for FRPstrengthened concrete elements and is usually used for masonry elements as well. This bond-slip model can be obtained by identifying three parameters, namely the characteristic fracture energy, $G_{f}$, the elastic stiffness, $k_{1}$, and the ultimate slip, $s_{u}$.

A simplified relation is proposed in CNR DT200 [26] for calculating the characteristic fracture energy of the FRP-masonry elements, defined as the area under the bond-slip curve:

$$
G_{f}=c_{1} \sqrt{f_{M k} f_{M t m}}
$$

where $c_{1}$ is an empirical coefficient which should be obtained experimentally or can be assumed to be equal to $0.015 . f_{M k}$ is the characteristic compressive strength of masonry, and $f_{M t m}$ is the average masonry tensile strength. The characteristic compressive strength can be evaluated according to the Eurocode 6 [29], see Eq. 6, and the masonry average tensile strength can be assumed to be equal to $10 \%$ of the characteristic compressive strength according to CNR DT200 [26]. Another approach for obtaining 
the characteristic values is multiplying the mean values by $1 / 0.7$, which is followed in this study for obtaining the characteristic compressive strength of masonry bricks.

$f_{M k}=K f_{c b}^{0.7} f_{c m}^{0.3}(6)$

where $K$ is assumed to be equal to 0.55 , and $f_{c b}$ and $f_{c m}$ are the compressive strengths of brick and mortar, respectively.

The slope of the elastic part of the bond-slip law can be calculated as:

$$
k_{1}=\frac{c}{\frac{t_{a}}{G_{a}}+\frac{t_{M}}{G_{M}}}
$$

where for $c$ a range of 0.5 to 0.7 is suggested ( 0.5 was selected for this study), $t_{a}$ and $t_{M}$ are the adhesive and masonry nominal thickness, and $G_{a}$ and $G_{M}$ are the adhesive and masonry shear moduli, respectively. For the value of ultimate slip, $s_{u}$ in Fig. 15, CNR DT200 suggests a range of between 0.2 and $0.3 \mathrm{~mm}$.

These parameters are calculated following the CNRDT200 approach and are presented in Table 3.Moreover, the corresponding bond-slip curves are compared with those proposed in this study in Fig. 16.

Assuming the value of 0.015 for the parameter $c_{1}$ resulted in a low fracture energy, $0.098 \mathrm{~N} / \mathrm{mm}$, compared to the experimental fracture energy. For this reason, this parameter has been obtained experimentally by rewriting Eq. (5) as follows, see Table 4:

$$
c_{1}=\frac{G_{f}}{\sqrt{f_{M k} f_{M t m}}}
$$

Comparison of the CNR DT200 bond-slip model with the proposed bond-slip model and experimental bond behavior, see Fig. 16, shows that the bond-slip model 
proposed by CNR DT200 differs slightly from the observed experimental bond behavior in GFRP-, BFRP-, and SRP-strengthened specimens. This difference is more clearly observed in peak strength values, which are always higher than experimental and numerical results. The maximum slip differs slightly from the experimental envelope, see Table 5, but it does not greatly affect the global behavior since the same fracture energy has been obtained. The stiffness of the bond-slip model falls inside the experimental envelope when the parameter $c$ is set equal to 0.5 as the best choice.

An issue worth noting is that the bond-slip model proposed in CNR DT200 is similar for different FRP types. For instance, the predicted bond-slip models for CFRP-, GFRP-, and BFRP-strengthened bricks are almost the same, while different behavior has been observed in the presented experimental and numerical results in terms of local bond behavior and global force-relative displacement curves. The results show that the bond-slip behavior is a function of mechanical properties of both the composite material and substrate, taking into consideration the governing failure mode, which should be considered in design procedures. However, it is still necessary to perform comprehensive experimental and numerical studies to propose such a general bond-slip model for FRP-strengthened masonry elements.

\section{CONCLUSIONS}

In this paper a review of the main results of an experimental campaign on the shear bond behavior of composite materials (GFRP, CFRP, BFRP, and SRP) applied to clay bricks is presented. A modeling strategy based on the use of interface elements has been used to investigate the experimental bond behavior of the reinforced specimens. Numerical simulation of the local (bond stress-slip) and global (force-relative displacement) behavior represents the key aspect of the paper, together with proposing the use of a trilinear bond-slip relationship derived from the experimental tests. 
The experimental tests contain standard bricks strengthened with CFRP (carbon fiber reinforced polymers), GFRP (glass fiber), BFRP (basalt fiber), and SRP (steel) composite material. Newer materials (BFRP and SRP composites) had a suitable bond behavior while having some advantages compared to the others.

The proposed bond-slip model has been validated by comparing the experimental and numerical results. A good agreement has been found between the analysis and experimental results in terms of global and local behavior. This agreementis also found in highly nonlinear ranges of behavior $(80 \%$ of the peak load),confirming the accuracy of the adopted method and appropriate selection of the bond-slip model.

A comparison is performed between the proposed bond-slip model and the one proposed by the Italian design code CNR DT200, and some relevant aspects for design procedures are presented. It is shown that the code proposes the same bond-slip model for strengthened masonry with different FRP types. However, results presented in this study showed that the bond behavior varies from one FRP type to another, depending on the mechanical properties and governing failure mode.

\section{ACKNOWLEDGEMENTS}

This work was partly funded by project FP7-ENV-2009-1-244123-NIKER of the 7th Framework Programme of the European Commission, which is gratefully acknowledged. The experimental results mentioned in the paper were obtained within the framework of the RILEM TC 223-MSC activities, for which the authors are grateful. 


\section{REFERENCES}

[1] Bonaldo E, Barros JO, Lourenço PB. Bond characterization between concrete substrate and repairing SFRC using pull-off testing. Int J Adhes Adhes 2005; 25(6):463-74.

[2] Yao J, Teng JG, Chen JF. Experimental study on FRP-to-concrete bonded joints. Compos: Part B 2005; 36(2):99-113.

[3] Pellegrino C, Tinazzi D, Modena C. Experimental study on bond behavior between concrete and FRP reinforcement. J Compos Constr 2008; 12(2):180-9.

[4] Maeda T, Asano Y, Sato Y, Ueda T, Kakuta Y. A study on bond mechanism of carbon fiber sheet. In: Proc Third Int SympNon-Metallic (FRP) Reinforced Concrete Structures, Sapporo, Japan, 1997.

[5] Sato Y, Kimuram K, Kobatake Y. Bond behavior between CFRP sheet and concrete. J Struct Constr Eng 1997; 500:75-82.

[6] Dai JG, Ueda T, Sato Y. Unified analytical approaches for determining shear bond characteristics of FRP-concrete interfaces through pullout tests. J Adv Concr Technol 2006; 4(1):133-45.

[7] CornettiP, CarpinteriA. Modeling the FRP-concrete delamination by means of an exponential softening. Eng Struct 2011; 33(6):1988-2001.

[8] Wu Y, ZhouZ, Yang Q, Chen W. On the bond strength of FRP-concrete structures. Eng Struct 2010; 32(3):897-905.

[9] Wu Z, Wu Y, Yun Y. Analytical modeling of the bond-slip relationship at interfaces for adhesively-bonded joints. Compos: Part B 2010; 41(6):423-33. [10] Lu XZ, Ye LP, Teng JG, Jiang JJ. Meso-scale finite element model for FRP sheets/plates bonded to concrete. Eng Struct 2005; 27(4):564-75. 
[11] Chen JF, Pan JW. Three dimensional stress distribution in FRP-to-concrete bond test specimens. Constr Build Mater 2006; 20(1/2):46-58.

[12] Aiello MA, Sciolti SM. Bond analysis of masonry structures strengthened with CFRP sheets. Constr Build Mater 2005; 20(1/2):90-100.

[13] Ceroni F, Pecce M, Manfredi G, Marcari G. Experimental bond behavior in masonry elements externally reinforced with FRP laminates. In: Proc Int Conf Composite Constructions, Cosenza, Italy, 2003.

[14] Capozucca R. Experimental FRP/SRP-historic masonry delamination. Compos Struct 2010; 92(4):891-903.

[15] Oliveira DV, Basilio I, Lourenço PB. Experimental bond behavior of FRP sheets glued on brick masonry. J Compos Constr 2010; 14(3):312-23.

[16] La Mendola L, Failla A, Cucchiara C, Accardi M. Debonding phenomena in CFRP strengthened calcernite masonry walls and vaults. Adv Struct Eng 2009; 12(5):745-60. [17] Garbin E, Panizza M, Valluzzi MR. Experimental assessment of bond behavior of fiber-reinforced polymers on brick masonry. Struct Eng Int 2010; 20(4):392-99. [18] Willis CR, Yang Q, Seracino R, Griffith MC. Bond behavior of FRP-to-clay brick masonry joints. Eng Struct 2009; 31(11):2580-7.

[19] Grande E, Imbimbo M, Sacco E. Bond behavior of CFRP laminates glued on clay bricks: Experimental and numerical study. Compos: Part B 2011; 42(2):330-40. [20] Fedele R, Milani G. A numerical insight into the response of masonry reinforced by FRP strips. The case of perfect adhesion. Compos Struct 2010; 92(10):2345-57. [21] Fedele R, Milani G. Three-dimensional effects induced by FRP-from-masonry delamination. Compos Struct 2011; 93(7):1819-31. 
[22] Milani G, Milani E, Tralli A. Upper bound limit analysis model for FRP-reinforced masonry curved structures. Part I: unreinforced masonry failure surfaces. Comput Struct 2009; 87(23/24): 1516-33.

[23] Milani G. 3D FE limit analysis model for multi-layer masonry structures reinforced with FRP strips. Int J Mech Sci 2010; 52(6):784-803.

[24] Milani G, Milani E, Tralli A. Approximate limit analysis of full scale FRPreinforced masonry buildings through a 3D homogenized FE package. Compos Struct 2010; 92(4):918-35.

[25] Grande E, Milani G, Sacco E. Modeling and analysis of FRP-strengthened masonry panels. Eng Struct 2008; 30(7):1842-60.

[26] CNR-DT200. Guide for the design and construction of externally bonded FRP systems for strengthening existing structures. National Research Council (CNR), Italy, 2009.

[27] Valluzzi MR, Oliveira DV, Caratelli A, Castori G, Corradi M, de Felice G, Garbin E, Garcia D, Garmendia L, Grande E, Ianniruberto U, Kwiecień A, Leone M, Lignola GP, LourençoPB, Malena M, Micelli F, Panizza M, Papanicolaou CG, Prota A, Sacco E, Triantafillou TC, Viskovic A, Zając B, Zuccarino G. Round robin test for compositeto-brick shear bond characterization. Mater Struct 2012 (submitted).

[28] DIANA. Displacement analysis finite element software. V. 9.4, TNO Building Division, Delft, The Netherlands, 2009.

[29] Eurocode 6. Design of masonry structures, Part 1-1: General rules for building Rules forreinforced and unreinforced masonry. European Committee for Standardization, CEN,Brussels, Belgium, 2005. 


\section{List of tables}

Table 1. Characteristics of the composite materials.

Table 2. Parameters used in the numerical simulations for the proposed bond-slip model.

Table 3. Parameters of the bond-slip model proposed by CNR DT200 [26].

Table 4. Experimental values of parameter $c_{1}$.

Table 5. Comparison of the values for ultimate slip.

\section{List of figures}

Fig. 1. Geometry of the FRP-masonry brick specimens.

Fig. 2. Experimental strain distributions along the bonded length (only the first specimen is shown): (a) CFRP-, (b) GFRP-, (c) BFRP-, (d) SRP-strengthened specimens.

Fig. 3. Local bond stress-slip curves (the envelopes of six tests are shown): (a) CFRP-,

(b) GFRP-, (c) BFRP-, (d) SRP-strengthened specimens.

Fig. 4. Experimental force-relative displacement curves for all strengthened specimens:

(a) CFRP; (b) GFRP; (c) BFRP; (d) SRP.

Fig. 5. Envelope of experimental force-relative displacement curves.

Fig. 6. Finite element model.

Fig. 7. Different bond-slip models used for FRP-strengthened concrete and masonry.

Fig. 8. Proposed trilinear bond-slip model.

Fig. 9. Comparison of numerical and experimental force-relative displacement curves:

(a) CFRP-, (b) GFRP-, (c) BFRP-, (d) SRP-strengthened specimens.

Fig. 10. Comparison of numerical and experimental strain distributions: (a) CFRP-, (b) GFRP-strengthened specimens. 
Fig. 11. Comparison of numerical and experimental strain distributions: (a) BFRP-, (b) SRP-strengthened specimens.

Fig. 12. Comparison of the adopted bond-slip model and experimental bond behavior:

(a) CFRP-, (b) GFRP-, (c) BFRP-, (d) SRP-strengthened specimens.

Fig. 13. Normal stresses along the FRP composites.

Fig. 14. Stress contours in the bricks for the maximum principal stresses: (a) CFRP-, (b) GFRP-, (c) BFRP-, (d) SRP-strengthened specimens.

Fig. 15. Bilinear bond-slip law proposed by CNR DT200 [26].

Fig. 16. Bond-slip models proposed by CNR DT200 [26]: (a) CFRP-, (b) GFRP-, (c) BFRP-, (d) SRP-strengthened specimens. 
Table 1. Characteristics of the composite materials.

\begin{tabular}{|c|c|c|c|c|}
\hline Material & $\begin{array}{c}E_{f} \\
(\mathrm{MPa})\end{array}$ & $\begin{array}{c}f_{t} \\
(\mathrm{MPa})\end{array}$ & $\begin{array}{c}\varepsilon_{\max } \\
(\%)\end{array}$ & $\begin{array}{c}t_{f} \\
(\mathrm{~mm})\end{array}$ \\
\hline CFRP & 202070 & 2525 & 1.16 & 0.17 \\
\hline GFRP & 77160 & 1350 & 1.86 & 0.12 \\
\hline BFRP & 86090 & 1499 & 1.74 & 0.14 \\
\hline SRP & 192910 & 2876 & 1.66 & 0.23 \\
\hline
\end{tabular}


Table 2. Parameters used in the numerical simulations for the proposed bond-slip model.

\begin{tabular}{|c|c|c|c|c|c|}
\hline Specimen & $\begin{array}{c}\tau_{\max } \\
(\mathrm{MPa})\end{array}$ & $\begin{array}{c}s_{0} \\
(\mathrm{~mm})\end{array}$ & $\begin{array}{c}s_{I} \\
(\mathrm{~mm})\end{array}$ & $\begin{array}{c}s_{u} \\
(\mathrm{~mm})\end{array}$ & $\begin{array}{c}G_{f} \\
(\mathrm{~N} / \mathrm{mm})\end{array}$ \\
\hline CFRP & 1.80 & 0.04 & 0.09 & 0.35 & 0.36 \\
\hline GFRP & 1.20 & 0.03 & 0.10 & 0.45 & 0.31 \\
\hline BFRP & 1.70 & 0.02 & 0.12 & 0.33 & 0.36 \\
\hline SRP & 1.80 & 0.02 & 0.10 & 0.20 & 0.25 \\
\hline
\end{tabular}


Table 3. Parameters of the bond-slip model proposed by CNR DT200 [26].

\begin{tabular}{|c|c|c|c|c|c|}
\hline Specimen & $c_{1}$ & $c$ & $K_{1}$ & $\begin{array}{c}\tau_{\max } \\
(\mathrm{MPa})\end{array}$ & $\begin{array}{c}G_{f} \\
(\mathrm{~N} / \mathrm{mm})\end{array}$ \\
\hline CFRP & 0.055 & & 103.89 & 2.38 & 0.36 \\
\hline GFRP & 0.048 & \multirow{3}{*}{0.50} & & 2.20 & 0.31 \\
\cline { 1 - 3 } \cline { 4 - 6 } BFRP & 0.052 & & 2.38 & 0.34 \\
\hline SRP & 0.038 & & & 1.65 & 0.25 \\
\cline { 1 - 3 } & & & &
\end{tabular}


Table 4. Experimental values of parameter $c_{1}$.

\begin{tabular}{|c|c|c|c|c|}
\hline Material & $\begin{array}{c}f_{\mathrm{mk}} \\
(\mathrm{MPa})\end{array}$ & $\begin{array}{c}f_{\mathrm{mtm}} \\
(\mathrm{MPa})\end{array}$ & $\begin{array}{c}G_{f} \\
(\mathrm{~N} / \mathrm{mm})\end{array}$ & $c_{1}$ \\
\hline CFRP & 28.57 & 1.5 & 0.36 & 0.055 \\
\hline GFRP & 28.57 & 1.5 & 0.31 & 0.048 \\
\hline BFRP & 28.57 & 1.5 & 0.34 & 0.052 \\
\hline SRP & 28.57 & 1.5 & 0.25 & 0.038 \\
\hline
\end{tabular}


Table 5. Comparison of the values for ultimate slip.

\begin{tabular}{|c|c|c|c|}
\hline \multirow{2}{*}{ Specimen } & \multicolumn{3}{|c|}{$\begin{array}{c}s_{\mathrm{u}} \\
(\mathrm{mm})\end{array}$} \\
\cline { 2 - 3 } & $\begin{array}{c}\text { Experimental } \\
\text { envelope }\end{array}$ & $\begin{array}{c}\text { Proposed } \\
\text { model }\end{array}$ & $\begin{array}{c}\text { CNR DT200 } \\
{[26]}\end{array}$ \\
\hline CFRP & $0.22-0.36$ & 0.35 & \multirow{2}{*}{$0.2-0.3$} \\
\hline GFRP & $0.37-0.48$ & 0.45 & \multirow{2}{*}{0.33} \\
\hline BFRP & $0.31-0.43$ & 0.33 \\
\hline SRP & $0.17-0.24$ & 0.20 & \multicolumn{1}{|c|}{} \\
\hline
\end{tabular}






Fig. 1. Geometry of the FRP-masonry brick specimens. 


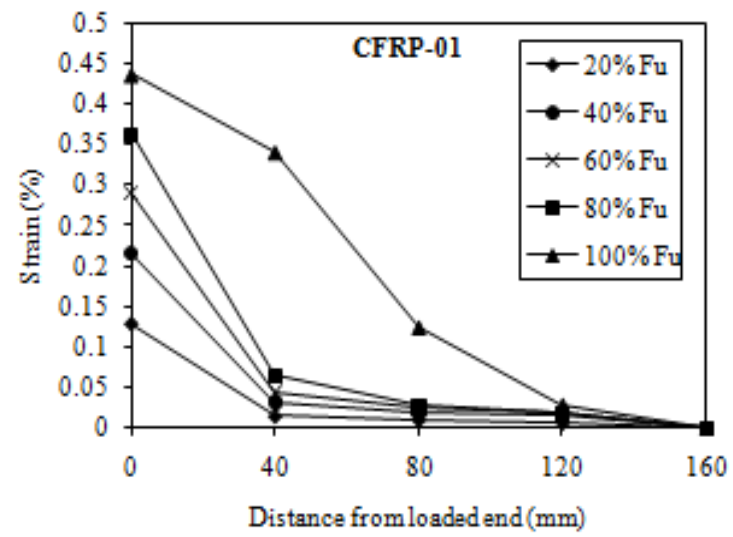

(a)

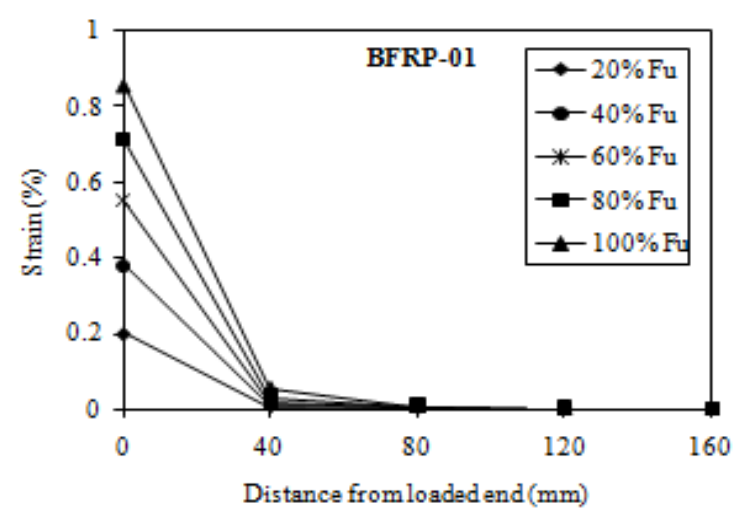

(c)

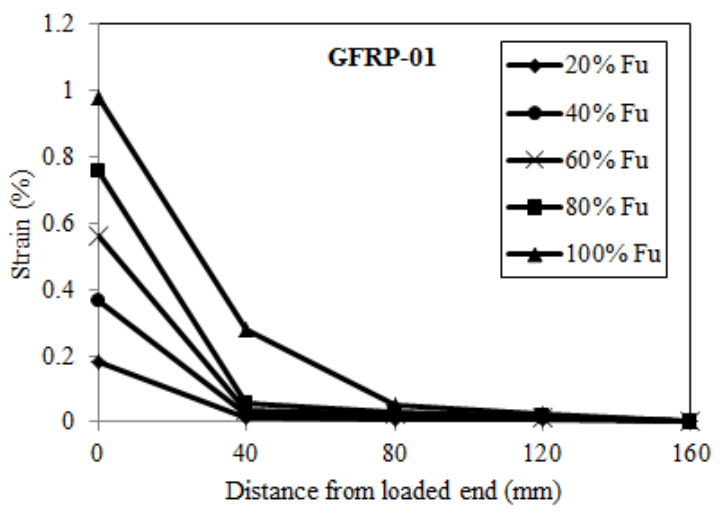

(b)

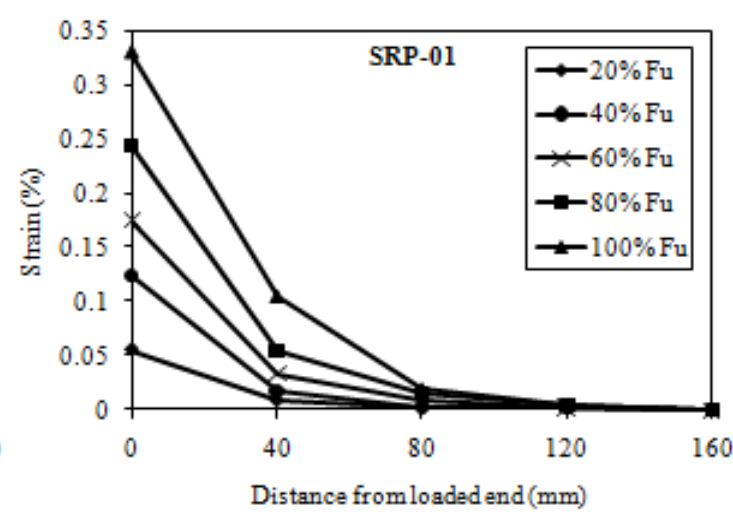

(d)

Fig. 2. Experimental strain distributions along the bonded length (only the first specimen is shown): (a) CFRP-, (b) GFRP-, (c) BFRP-, (d) SRP-strengthened specimens. 


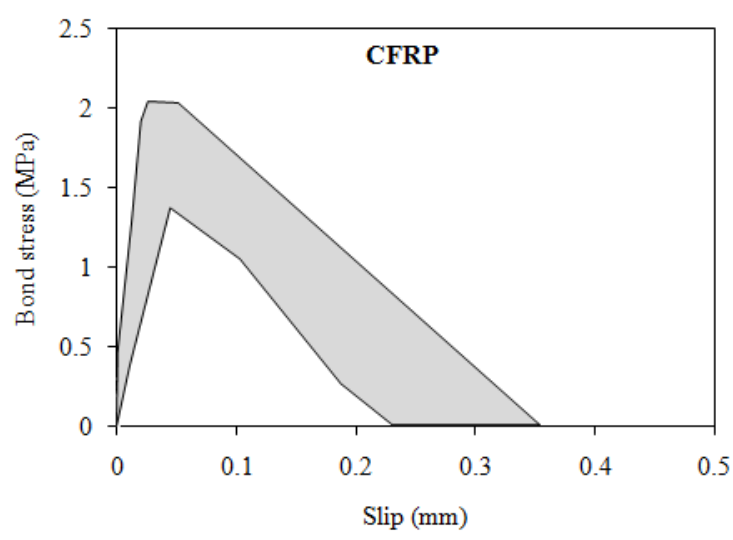

(a)

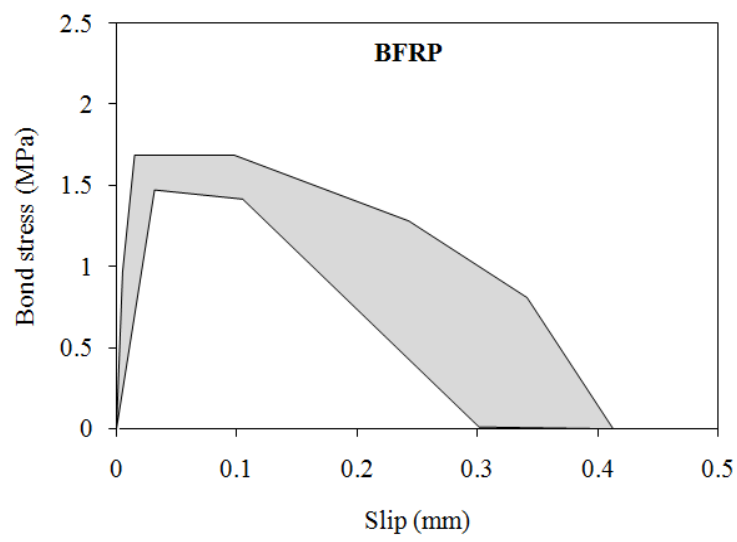

(c)



(b)

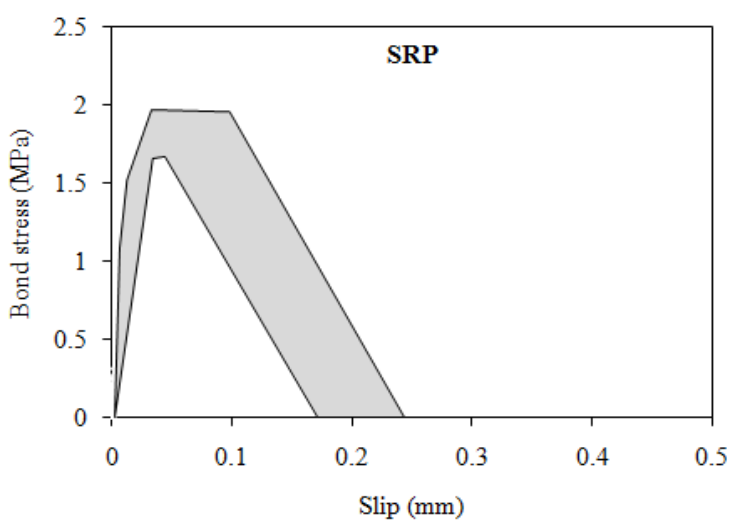

(d)

Fig. 3. Local bond stress-slip curves (the envelopes of six tests are shown): (a) CFRP-, (b) GFRP-, (c) BFRP-, (d) SRP strengthened specimens. 


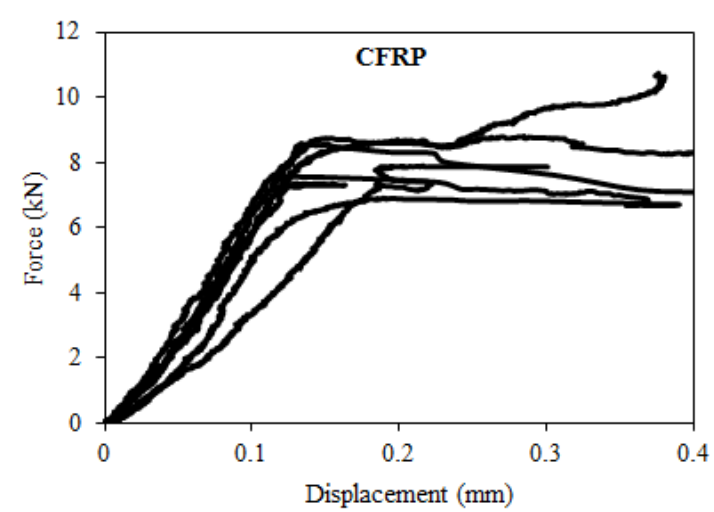

(a)

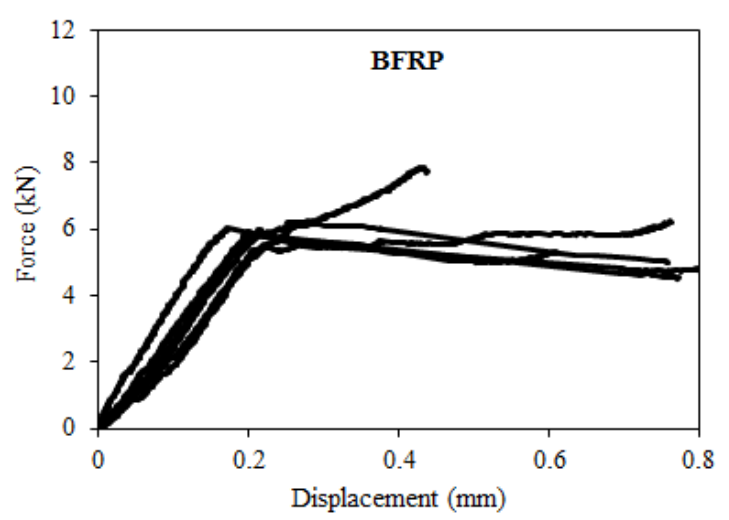

(c)



(b)

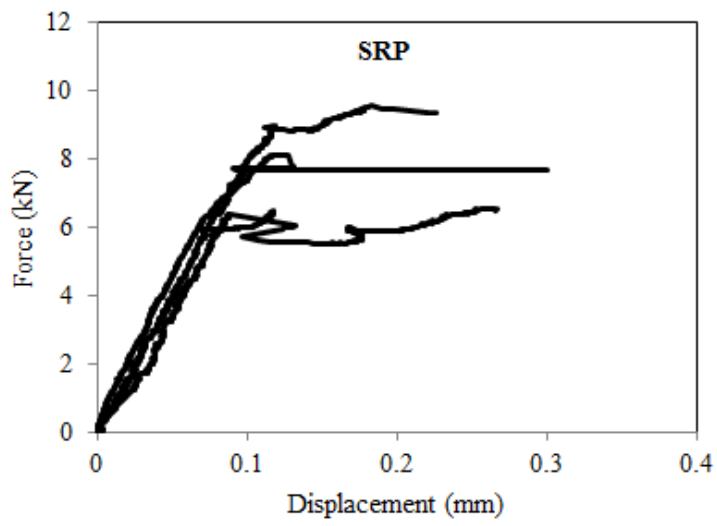

(d)

Fig. 4. Experimental force-relative displacement curves for all strengthened specimens:

(a) CFRP; (b) GFRP; (c) BFRP; (d) SRP. 


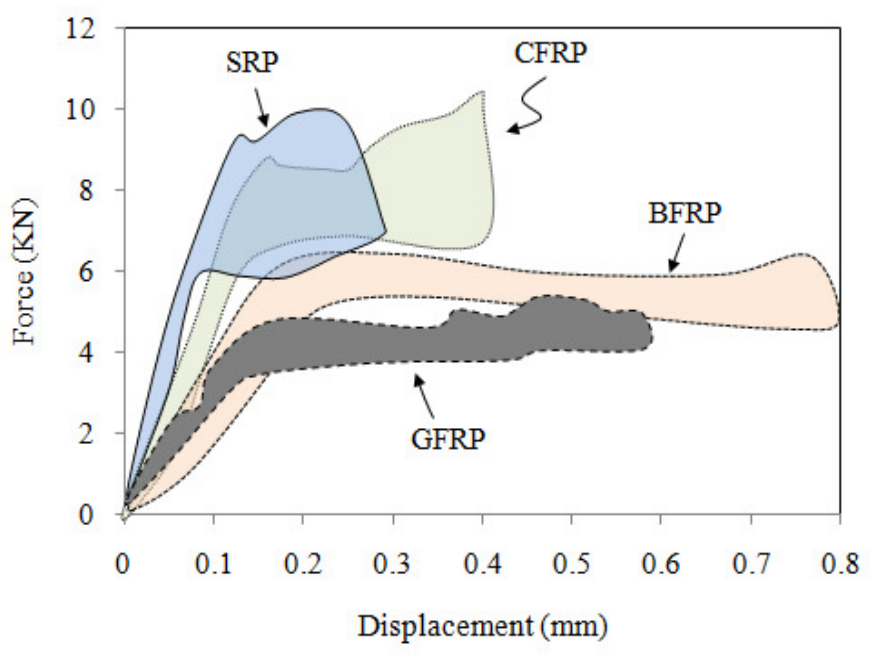

Fig. 5. Envelope of experimental force-relative displacement curves. 


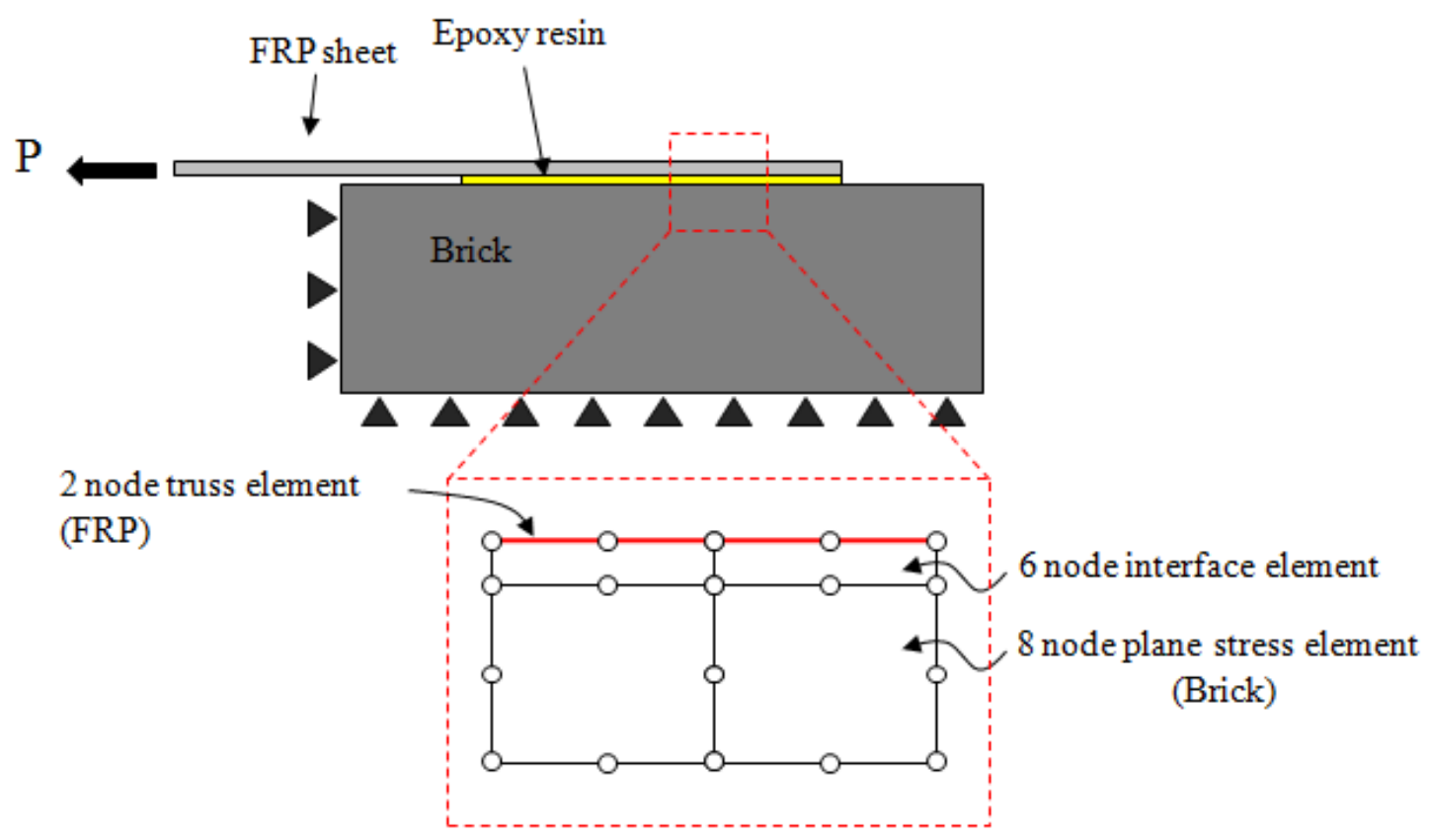

Fig. 6. Finite element model. 


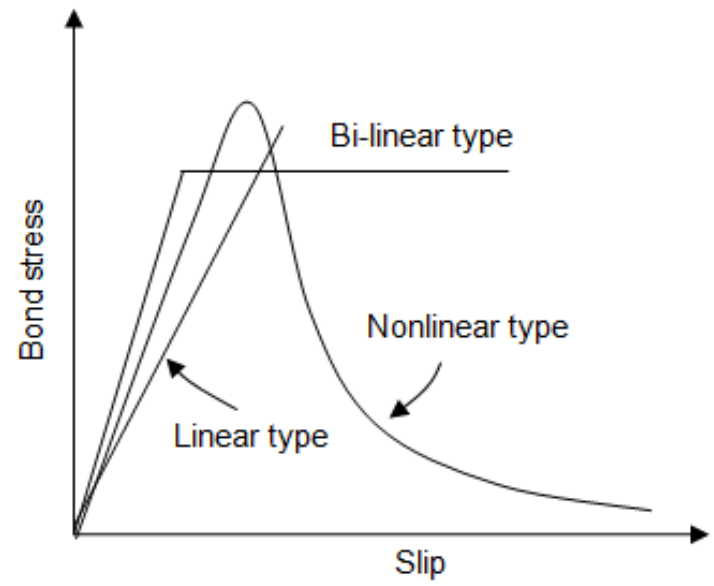

Fig. 7. Different bond-slip models used for FRP strengthened concrete and masonry. 


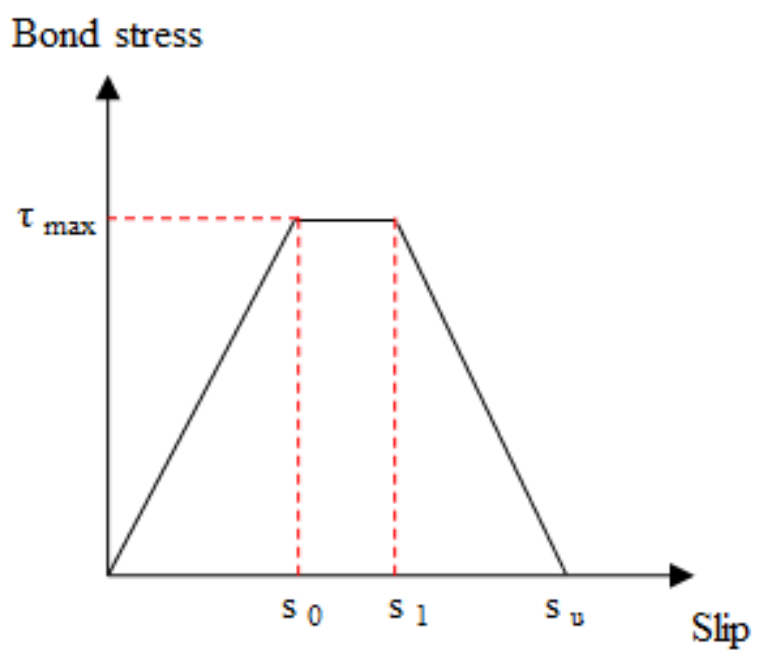

Fig. 8. Proposed trilinear bond-slip model. 


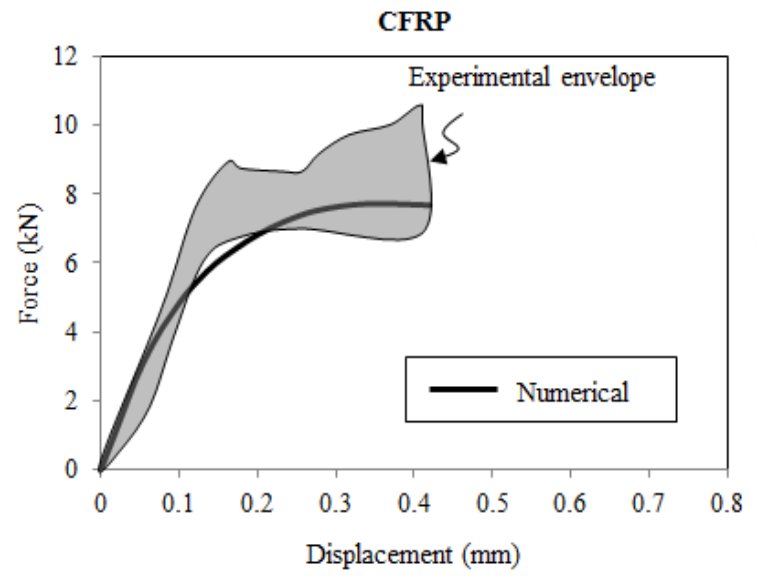

(a)

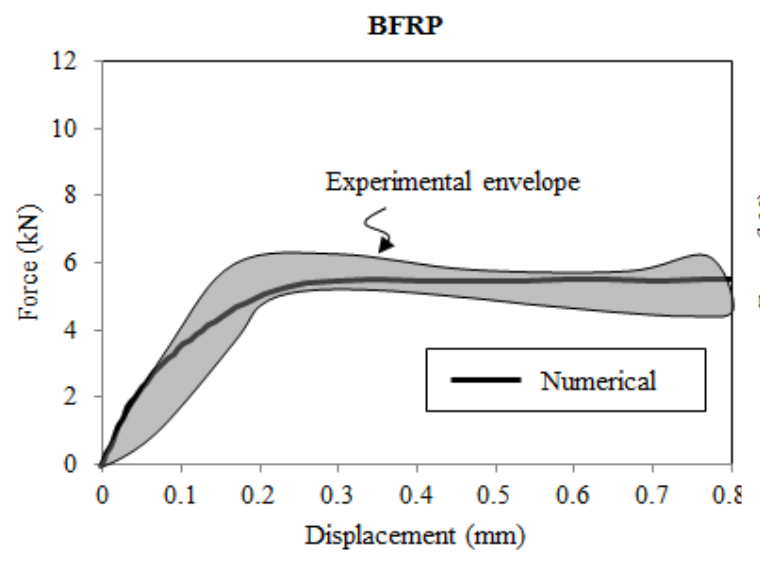

(c)

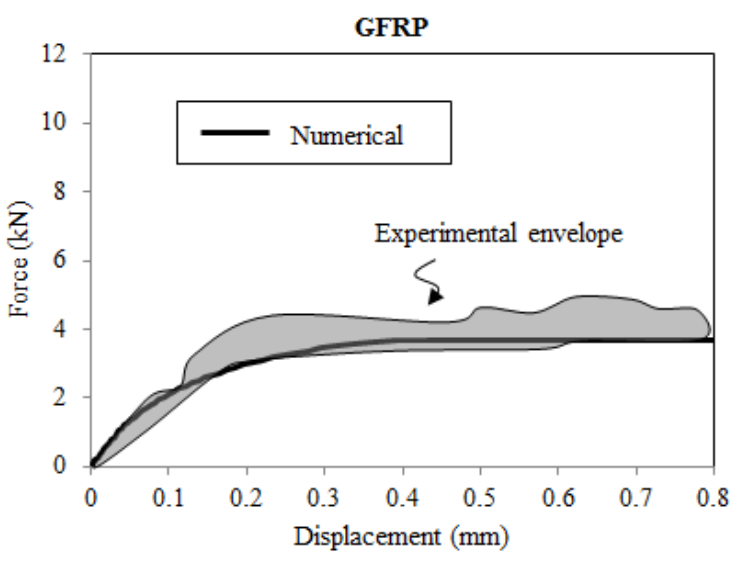

(b)

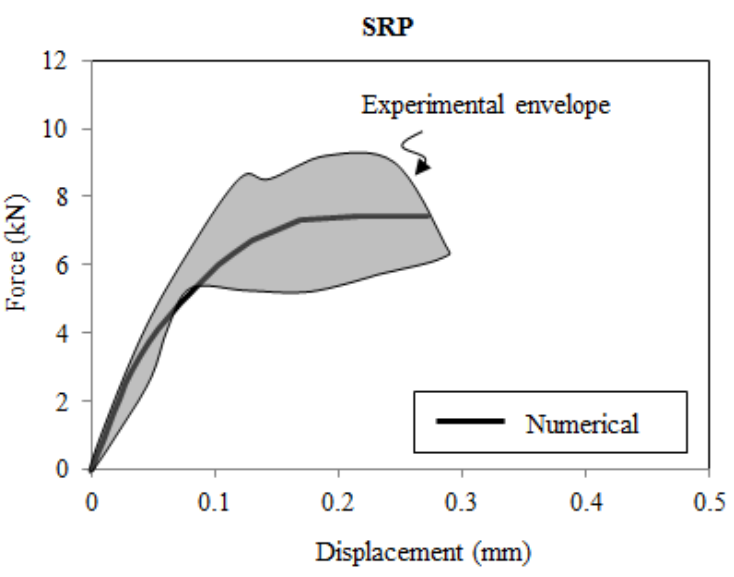

(d)

Fig. 9. Comparison of numerical and experimental force-relative displacement curves:

(a) CFRP-, (b) GFRP-, (c) BFRP-, (d) SRP-strengthened specimens. 

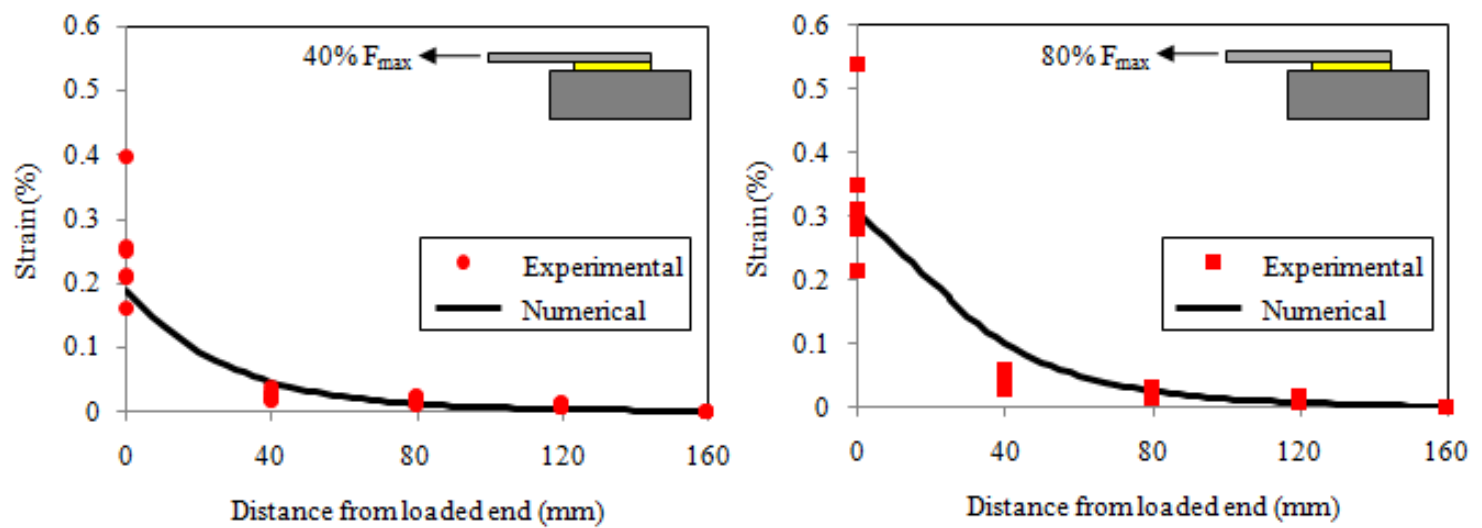

(a)
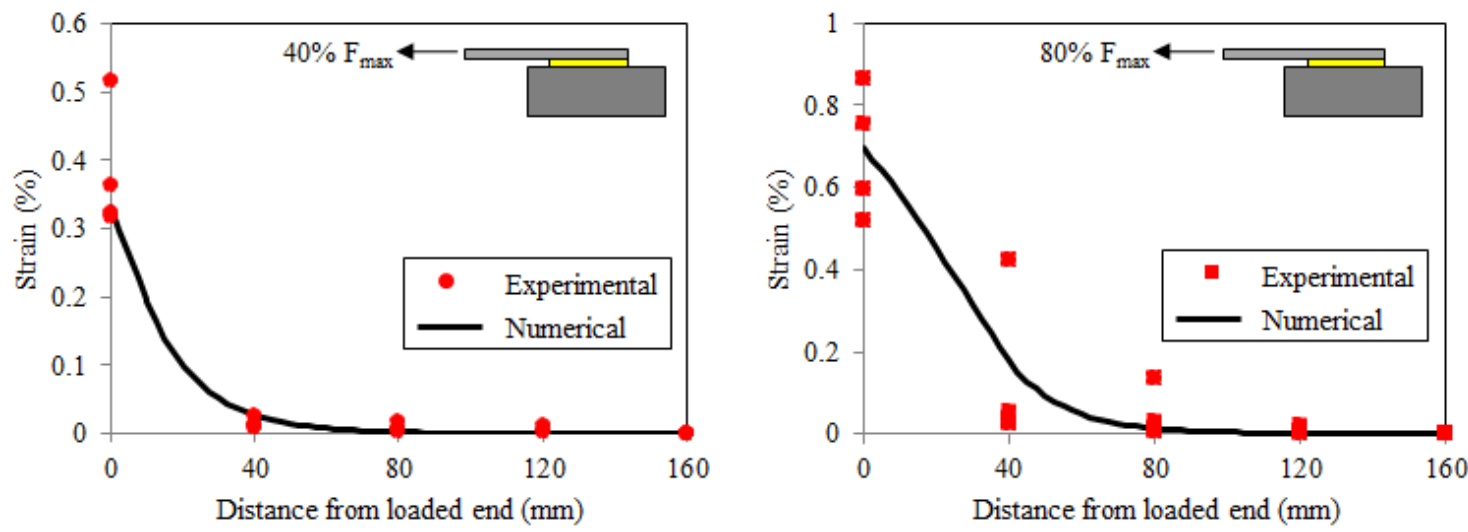

(b)

Fig. 10. Comparison of numerical and experimental strain distributions: (a) CFRP-, (b) GFRP-strengthened specimens. 

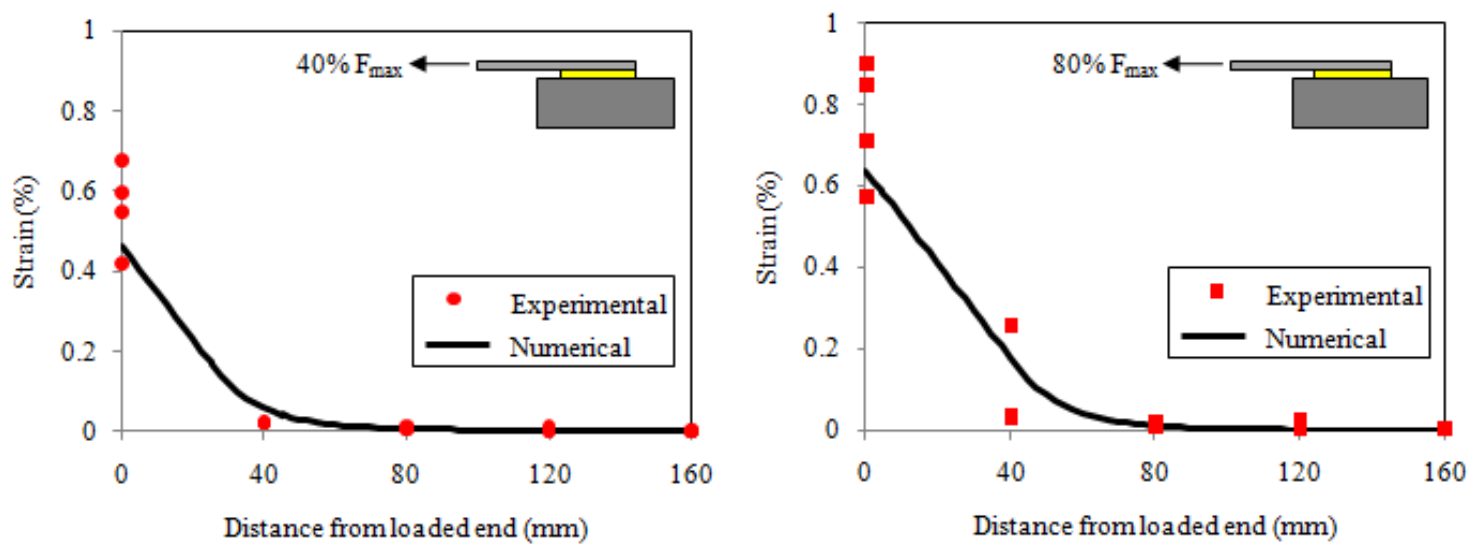

(a)
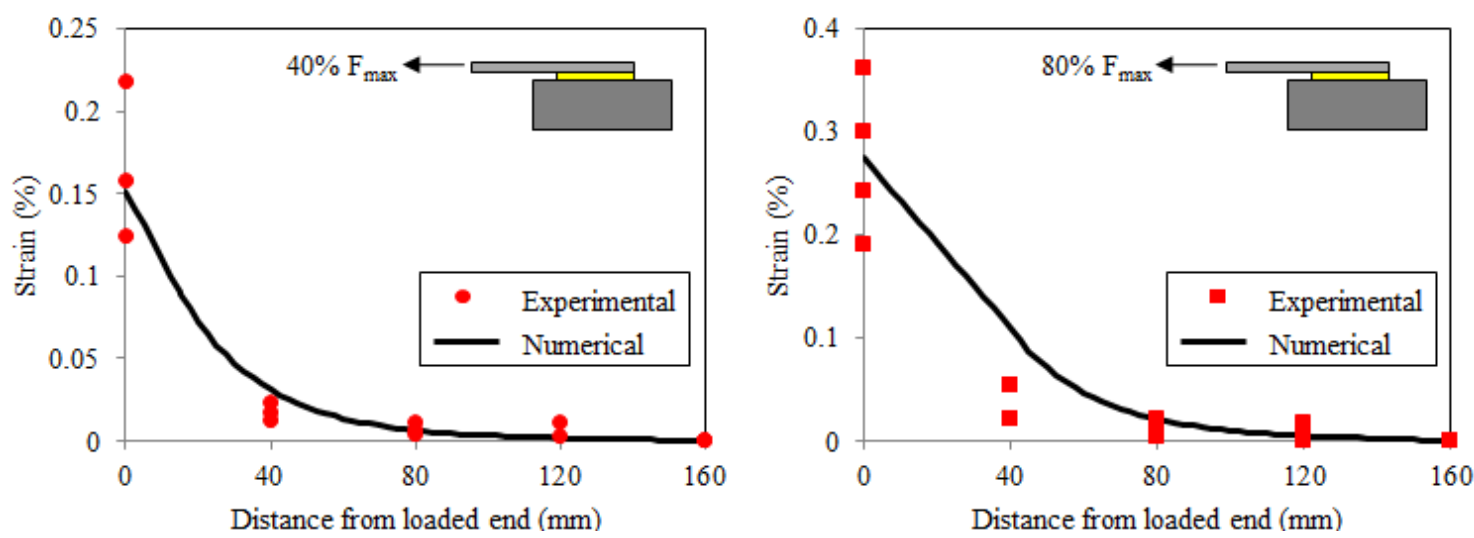

(b)

Fig. 11. Comparison of numerical and experimental strain distributions: (a) BFRP-, (b) SRP-strengthened specimens. 


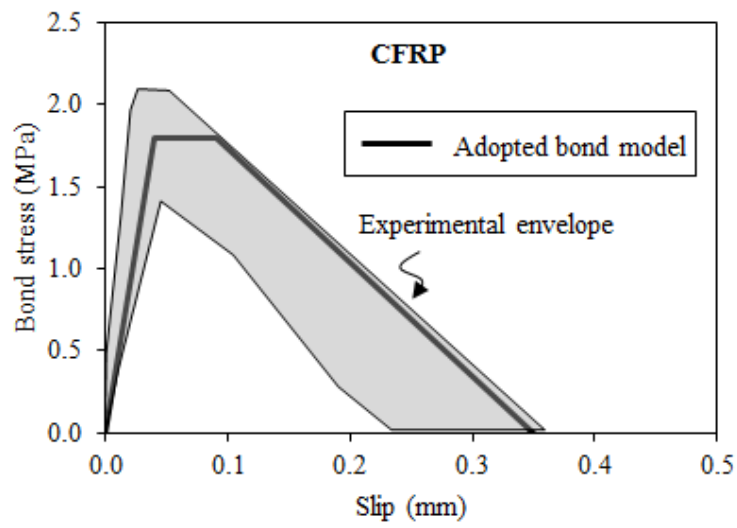

(a)

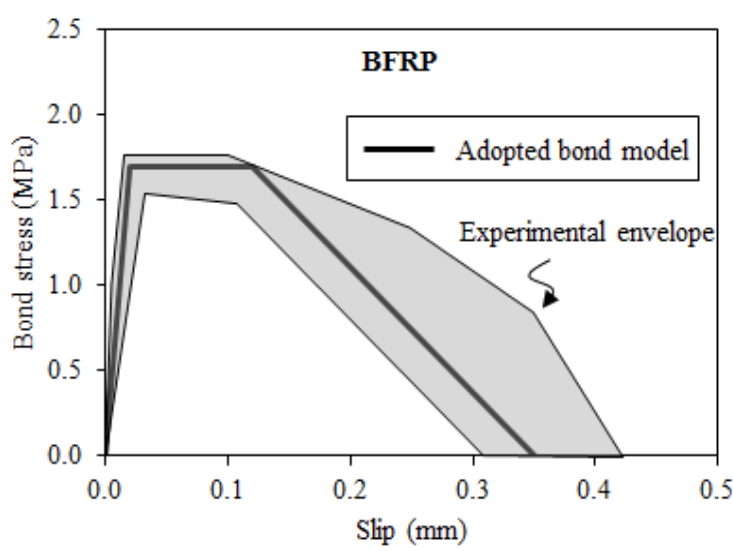

(c)

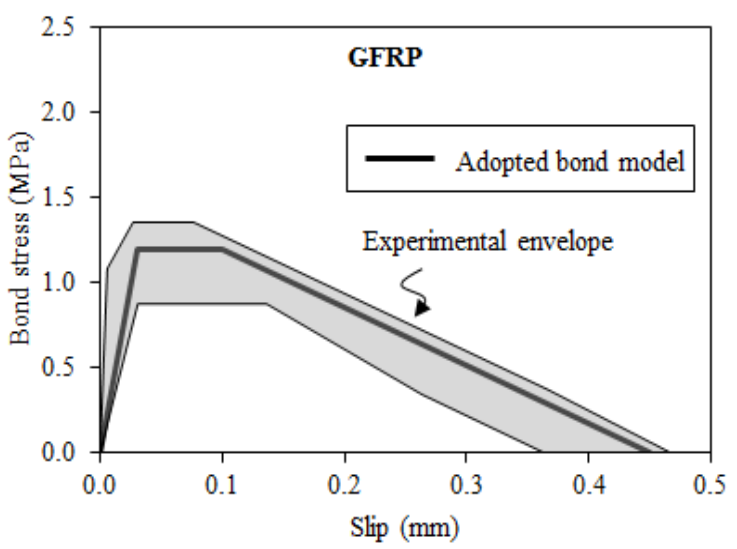

(b)



(d)

Fig. 12. Comparison of the adopted bond-slip model and experimental bond behavior:

(a) CFRP-, (b) GFRP-, (c) BFRP-, (d) SRP-strengthened specimens. 


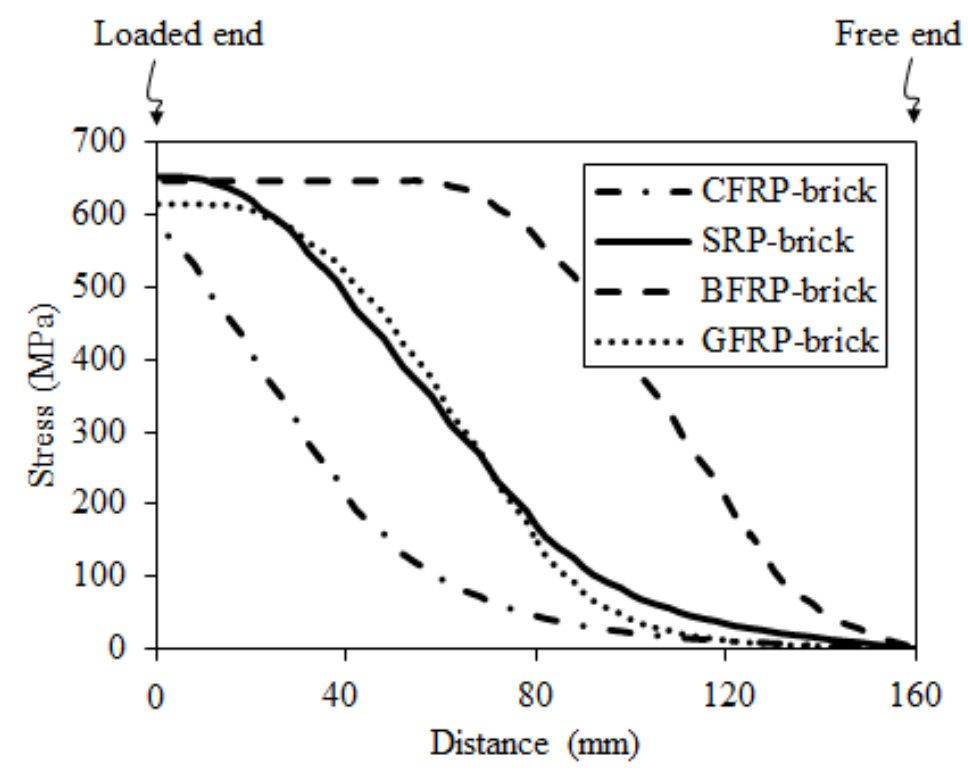

Fig. 13. Normal stresses along the FRP composites. 


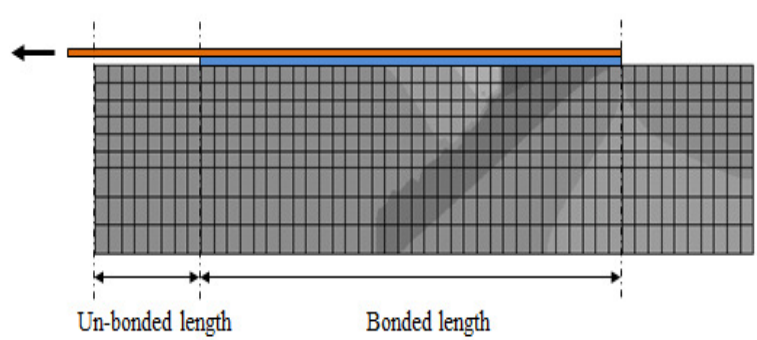

(a)

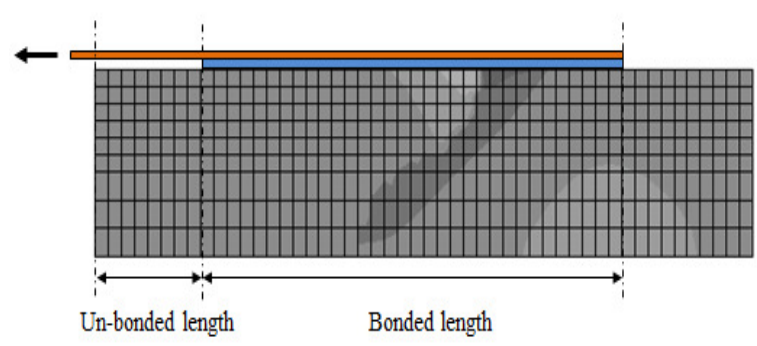

(c)

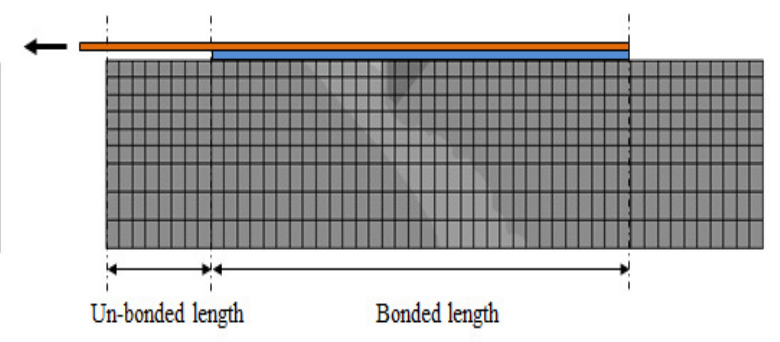

(b)

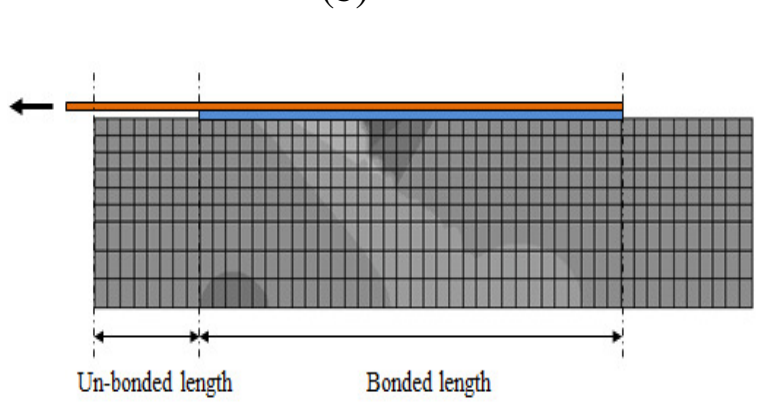

(d)

Fig. 14. Stress contours in the bricks for the maximum principal stresses: (a) CFRP-, (b) GFRP-, (c) BFRP-, (d) SRP-strengthened specimens. 


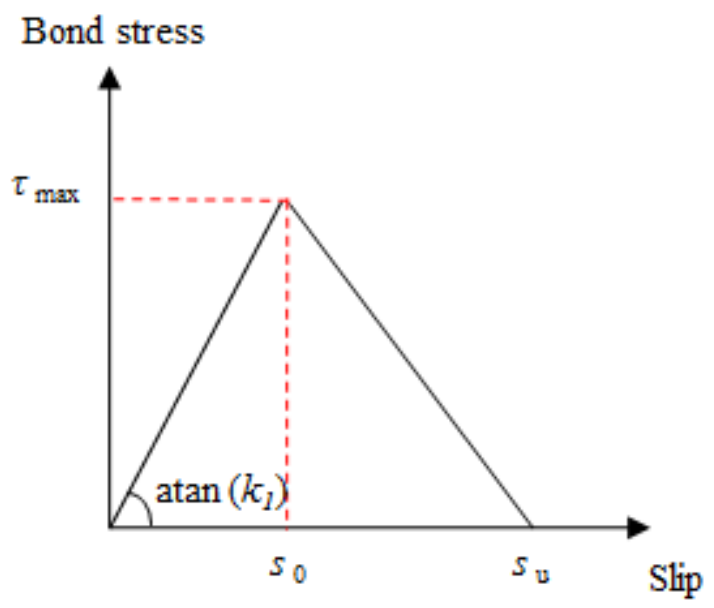

Fig. 15. Bilinear bond-slip law proposed by CNR DT200 [26]. 


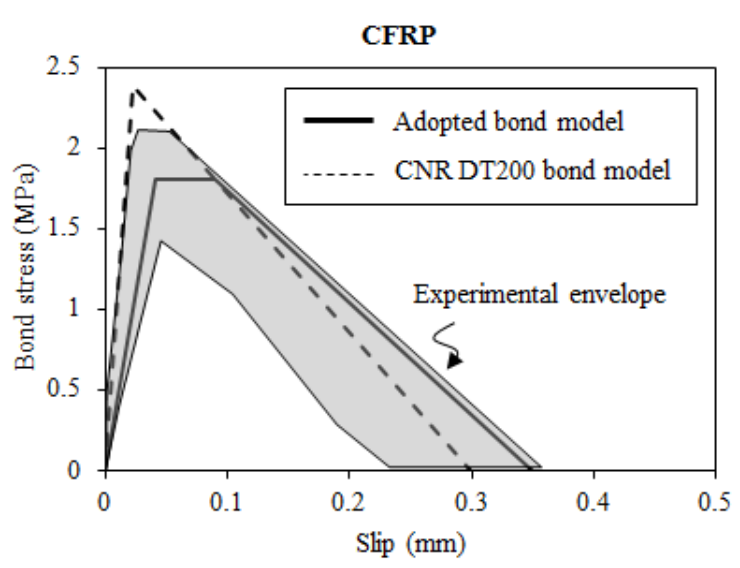

(a)

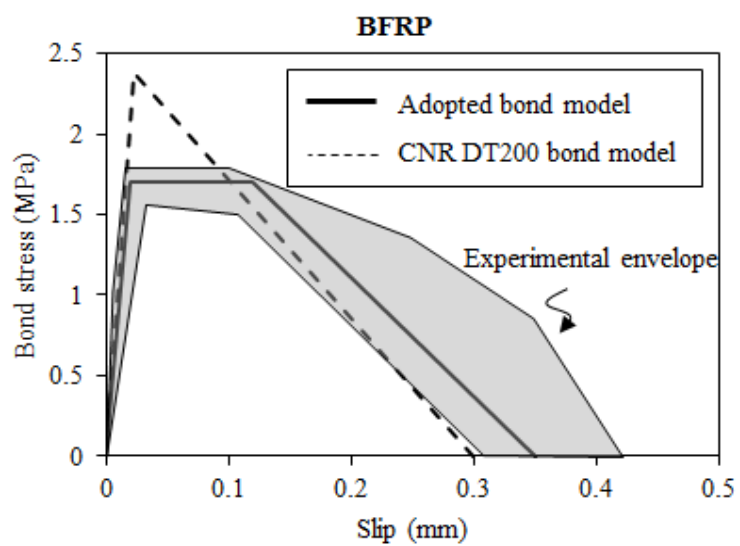

(c)

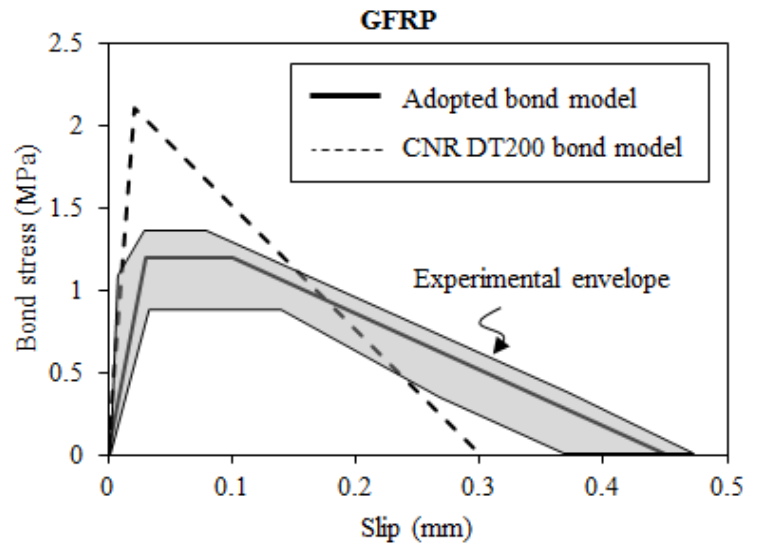

(b)

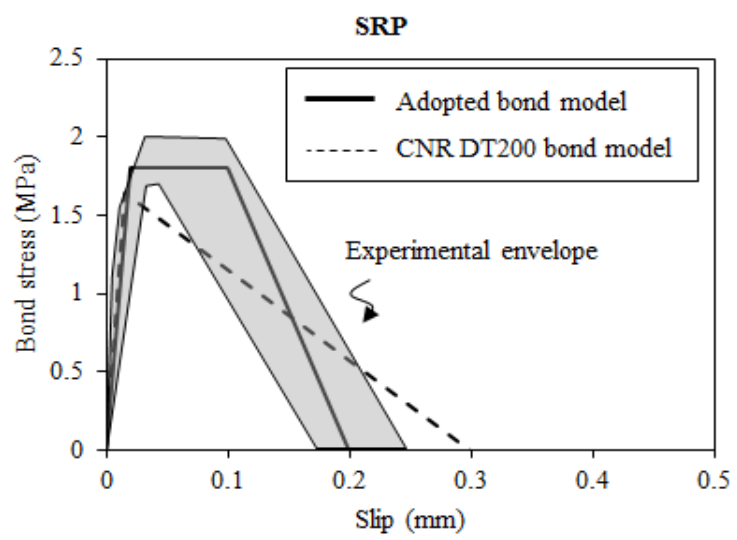

(d)

Fig. 16. Bond-slip models proposed by CNR DT200 [26]: (a) CFRP-, (b) GFRP-, (c) BFRP-, (d) SRP-strengthened specimens. 